\title{
Hauntology, Performance and Remix: Paradise // Now?
}

\section{Edyta Lorek-Jezińska}

Nicolaus Copernicus University in Toruń lorek@umk.pl

Received 5 August 2017; accepted 30 October 2017.

\begin{abstract}
Drawing upon concepts of hauntology and spectrality and their applications in performance and media theory, the article investigates the relation between live performance, performative memory and technology in Komuna Warszawa's project Paradise Now? RE//MIX Living Theatre. Premiered in 2013 as the 31 st part of the remix sequence bringing together the past works of international experimental artists and theatres and present-day Polish performers and dancers, Paradise Now remix offers a critical and self-referential commentary on what is left after the demise of political theatre and the utopian dream of paradise. My main argument focuses on the technological processes by which Komuna Warszawa spectralizes both the memory of the Living Theatre's Paradise Now and its own performance through re-mediating, digitizing and remixing fragmentary images and scenes. Their ultimate effect is a melancholic sense of disappearance, impossibility and technologically produced vacuum.
\end{abstract}

Keywords: hauntology; performance; technology; remix; the Living Theatre; Komuna Warszawa. 
To be haunted by a ghost is to remember what one has never lived in the present, to remember what, in essence, has never had the form of presence. (Derrida, 2013, p. 38)

So in some kind of rhetorical legerdemain, we keep up the plot, the archival burial ground, saying all the while that the life or afterlife of texts is all their own, and not an effect of embalming processes in which we engage. (Wolfreys, 2002, p. xii)

\section{Introduction: Hauntology, Remix and the Living Theatre}

Perhaps as a result of the ubiquity of ghosts following the spectral turn in contemporary literary and cultural criticism and theory (Weinstock, 2013, pp. 62-63), haunting has become a powerful metaphor that can be used quite surprisingly to explain the modes of existence of both live performance and mediated and recorded image and action. Hauntology can be applied in theatre studies to conceptualize significant aspects of live performance. ${ }^{1}$ The argument that theatre is the medium that is particularly haunted and determined by its own spectrality has been put forward by some scholars, emphasizing the theatre's authenticity and immediacy as well as its problematic reproducibility. The theatre's evanescence and its concrete materiality make exact reproduction and effective archiving impossible. The primary application of hauntology in performance studies serves the description of the ephemeral nature of a theatrical event and its inherent irreproducibility. The concept of haunting is also used to expose the significance of performative memory, in which theatre events are stored. This aspect is further related to the questions of archiving and documenting performance. Theatre documentation as such can be understood in terms of spectralisation; in this context hauntology helps to embrace the peculiar relation between the live event and recorded image. In this field it overlaps with its ostensible opposite and another haunted phenomenon, the haunted media. ${ }^{2}$

All of the abovementioned conceptual aspects of performance and its mediated versions are actively deployed in the project by the Warsaw-based theatre company Komuna Warszawa entitled Paradise Now Re//Mix Living Theatre, which premiered in 2013. Paradise Now? Re//Mix is a part of the performance sequence realized between 2010 and 2014 together with other artists. The project consists of a series of stage productions, each devoted to a significant contributor to the history of performance and dance. Among the artists whose works were remixed in the sequence one can find Oskar Schlemmer, John Cage, Pina Bausch, Robert Wilson, Laurie Anderson, Jerzy Grotowski, Tadeusz Kantor, Dario Fo, Carolee Schneemann and many others. Beside the project commemorating the American

\footnotetext{
${ }^{1}$ In a sense the very concept of hauntology as developed by Jacques Derrida in Specters of Marx partly originates in drama and theatre, being inspired by Shakespeare's Hamlet. Acting has been conceptualized as haunting or being haunted by theatre critics and practitioners, such as Tadeusz Kantor or anthropologists seeing origins of theatre in shamanistic rituals and possession by spirits. See E. Lorek-Jezińska (2013, pp. 33-38). Carlson's idea of the haunted stage will be mentioned further in the article.

${ }^{2}$ Also in Specters of Marx Derrida comments on the spectralizing quality of the media as existing beyond the notion of ontology and thus demanding a new category — the one of hauntology (Derrida, 2006, p. 63).
} 
alterative and political theatre - the Living Theatre - founded by Judith Malina and Julian Beck in 1947 in New York, Komuna Warszawa was engaged in the remix performances for Kartagina by a legendary Polish theatre company Akademia Ruchu (2010) and in the project called Komuna Warszawa vs. Majakowski (2011) (Plata \& Sajewska, 2014, pp. 254-265).

According to the description on Komuna Warszawa's web pages, remix is a concept adapted from music, which can be defined as a work in which the fragments, or samples, of the original are present as quotations. Despite its derivative character, remix can also function as a new piece of art "engag[ing] with the original through its form or content, entering into dialogue with it, nostalgically recalling it or finding in it new meanings" (Komuna Warszawa, 2015b). The remix formula involves processes that can be described in terms of haunting and spectrality. Remix relies on the interaction between the past theatrical and artistic projects and the present time, filtered through memory and documentation. It can be conceptualized as a form of resurrection of the past or perhaps more adequately as haunting of the present by what is gone. By referring to the past artistic projects, RE//MIX emphasizes connection, continuity and influence, but also a desire to break with the impact of the past tradition by spectralizing and mediatizing the original. In doing so, the remix performance is positioned between the two impossible but compelling options: annulling the past by transforming it into digitalized images or remembering it, which, like remembering the dead, is "neurotic and obsessive . . . and feeds a sterile repetition" (Jameson, 2008, p. 58).

In his study of remix and remix culture Eduardo Navas distinguishes between four types of remix, three of which might be particularly useful in the contextualization of the project under consideration. The selective remix is based on adding or subtracting elements from the original but preserving its general "spectacular aura" while the reflexive remix challenges the original and claims its own autonomy, but contains recognizable elements from the source (at least recognizable as alien in the target form; Navas, 2012, p. 66). The third form of remix - the regenerative one - although not directly applicable here for its mostly digital communication contexts - can be associated with the processes of onstage digitalization going on in Komuna Warszawa's project. As Navas argues, "while [regenerative remix] liberates the forms that are cited from their original context, [it] opens itself up for ahistoricity, as well as misinterpretations. The principle of the regenerative remix is to subvert, not to recognize but to be of practical use" (2012, p. 73). The regenerative remix reaches the meta-level of "re-mediating the media" (James, 2016, p. 140) for its own sake. Komuna Warszawa's performance makes all of these types of remixes both active and problematic. Through its mechanized self-reflexivity the project asks questions of the choice and ethics of remixing both the original performance and the documentary material used in it. The remix project is deliberately torn between a drive of reconstruction and revival and critical de(con)struction of the original. The intention behind the remix concept, according to its curator Tomasz Plata, was to revive - to bring back to life - past artistic projects significant to a generation of artists on individual, non-representative or non-canonical basis and to integrate artists from different fields around them (Plata \& Sajewska, 2014, pp. 10-17). What Paradise Now? remix seems to be engaged in is 
demonstrating simultaneously the spectral inadequacy and irrelevance of the past political theatre and a kind of disaffected nostalgia for the political utopia and its innocent-and no longer possible - naivety.

The decision to remix the Living Theatre's performance with the use of video and computer technologies, sampling and imitating the fragments of the original recorded material, activates a number of conflicts and frictions. The Living Theatre, one of the longest running theatrical groups still active after Malina's death in 2015, has been dedicated to political and social activism, for a long time living as a commune, in which theatre was an integral element of life (Brook, 1990, pp. 69-70). Their basic aim was to change the world and restore the connections between people, following the utopian anti-war and anti-capitalist ideals. In their performances they often proclaimed the necessity of restoring the primacy of feeling and emotions over intellect and language, which are easy to manipulate and use as an alibi (Roose-Evans, 1973, pp. 157-159). They also emphasized the importance of corporeality, experience, personal and physical contact as well as presence (Pasquier, 1987, pp. 80-82). In the eyes of one of its creators, Julian Beck, Paradise Now was supposed to be "the act itself, primary and unrepeatable" and its form should "allow a release of spontaneous creative forces that could transform audiences and society" (Tylell, 1995, p. 226). It is both ironic and symbolic to transform this lively and "holy" (Brook, 1990, p. 70) theatre into a digitalized visual and auditory composition remixing the fragments of records into a different kind of intangibility characteristic of copies and replications.

By trying to confront the myth of the Living Theatre and its present afterlife, Komuna Warszawa's project explores the tensions between the immediate and the mediated, and the present and the past. Referring to the legacy of the Living Theatre and using multimedia resources, mixing film, photography and live acting, Paradise Now? remix investigates the (im)possibility of reproducing the archive of theatre history in live performance. The dominating principle that defines Komuna's performance is a sense of vanishing and emptiness created in a technologically induced vacuum, where the only meaningful and authentic element available is a filmed interview with Judith Malina, which seems inadequate as a memory and documentation of the Living Theatre's legacy. The interview was recorded by the company in 2013 in the Actors Home - two years before Malina's deathand is primarily concerned with the question of what paradise is nowadays (Gałązka, 2014, pp. 218-219). The performance exposes the processes of mediation at the cost of the mediated image and the memory of political theatre, creating the melancholic feeling of irrevocable loss of the past and the impossibility of the future.

In order to discuss the complexities of the remix process in Komuna Warszawa's performance, in the following part of the article I will refer to three major theoretical questions related to the concepts of haunting, performance and the media: the haunted stage and memory, the present time of performance and the concept of disappearance, and finally the haunted media and onstage digitalization. In Komuna Warszawa's performance all of these aspects are interrelated and run across both live performance and projected films and images. 


\section{The Haunted Stage and Memory_Paradise//}

The idea of the haunted stage used, among others as the title and the main concept of the 2003 book by Marvin Carlson, is primarily related to the concept of cultural memory that defines the experience of theatre. In the context of hauntological theory, a performance is compared to Derrida's revenant, which begins its existence by returning - reappearingpointing to the paradox of "beginning by coming back" (Derrida, 2006, p. 11). Each performance is constituted by repetition, by the return of the past productions and recognition of the familiar in the "audience's collective and individual memories of previous experience" (Carlson, 2003, p. 165). As a remix, the project by Komuna Warszawa relies on performative memory and recognition of the original performance. Yet this memory cannot be based on the actual experience and instead refers to its mediated versions, accounts, memoirs, documentaries, or scenarios. This indirect, mediated memory is subject to mythologization; the project's subversive and deconstructive strategies aim at comparison, juxtaposition and contrast between the nostalgic and mythologized image and what remains after the Living Theatre's performance today.

While Carlson uses the aspects of hauntology in the essentially intertextual meaning, which is highly significant in the remix formula, Komuna Warszawa's project seems to be engaged in the process of reducing all the performance components to the process of haunting in an almost literal sense. The fragments of the original performance-technologically transformed and reproduced-become detached from their original source and in a sense disembodied. It seems that the performance spectralizes itself by technological intervention and reproduction. The most representative example of this process is the complex act of spectralizing the live performance enacted on the stage. Recreating a fragment of the original production by the Living Theatre, the actors of Komuna Warszawa try to arrange the letters of the word paradise (in Polish) formed by their bodies. The live action is being filmed by several cameras, edited by several computers and then projected on the semi-transparent screen separating the performers from the audience. The meticulous technological reproduction of the original scene is devoid of the political engagement of the original. It exposes the inadequacy of the past form of political theatre in the context of the contemporary world. Similarly, the fragments of the original text are further divided, sometimes syllabified, superimposed on each other, repeated automatically without emotional engagement. By technological transformation, live action, live voice and the original texts and stage images are artificially reproduced while the aspects of performative memory based on experience are drastically reduced. The choreographic arrangements recreated on the basis of the original are separated from the audience by the screen, which makes any direct contact between performers and the audience impossible. This is a symbolic and spectacular negation of the proximity, participation and collective experience of the Living Theatre's original performance.

The culminating point of the production is a short film projected on the back screen presenting an actor of Komuna Warszawa who describes an act performed by the Living Theatre. This act involved diving from the stage or platform and falling into the arms of 
other performers and spectators. The two seconds of flight metaphorically present the utopia of paradise, which is so brief that it is almost non-existent. In the original performance the flying scene, devised by Ann Halprin (Innes, 1984, p. 250) and inspired by the Shamanistic ritual, comes to signify, as Innes argues, liberation and transcendence (Innes, 1993, pp. 187-188). The very act is built on trust, connection and interaction with other people. In the chanted words: "BREATHE... BREATHE... BREATHE... FLY" (Innes, 1984, p. 250), the emphasis is put on the moment of flying despite the fact that the act also involves the stage of falling down. In the performance by Komuna Warszawa the film presents a repeated sequence of the actor's body flying in the air, prolonging the moment of the flight endlessly. The actor describes the scene from the original performance in mythical unrealistic terms, referring to it as "rising into the air." Yet Komuna Warszawa's flying scene ends in the fall, as the actor repeats the sequence: "I breathe, I fly, I imagine, I see, I fly, I breathe, I see the paradise, I fall” (Luksza, 2014, p. 217; my translation) although the screen is blacked out before the fall actually happens. This artificially/miraculously generated simulacrum of utopia can be reproduced in a limitless repetition that only exposes the extent to which it can never become reality. Komuna Warszawa's performance - and the flying scene in particular - makes us aware of how the original performance easily yields to mythologization. To the generation that had no direct possibility of experiencing the Living Theatre's performance, it becomes accessible only in fragmentary documentation further deconstructed and fractured through the filmic and digital technologies which replace memory. This generational aspect surfaces in the company's description of the project and the questions asked therein: "So where are we, the commune, in all this? What else [is there], besides nostalgia, the touch of the legend? What else can we remember other than the afterimage of naked bodies gently twisting across the stage and revolutionary slogans shouted at the audience?" (Gałązka, 2014, p. 219; my translation). The performance provocatively asks what is left of political theatre and simultaneously answers: "What is left out of political art is art," adding almost offhandedly that in this case also an old woman and the question of paradise (Luksza, 2014, p. 214). The effect of various technological and conceptual strategies used by Komuna Warszawa can be seen as a deliberate travesty of political theatre, its formalistic antithesis.

\section{The Present Time of Performance and Disappearance—//now?}

In the remix project technological transformation also involves experimentation with the temporal aspects of performance and its phenomenology. Performance is often defined by the present time and its existence in the eternal now, ${ }^{3}$ which Szondi describes as "an absolute succession of "presents"' (as cited in Keir, 2002, p. 106). Yet the succession of presents involves also a succession of disappearances, which was described by Garner as "dys-appearance" accompanying "the presence of appearances" in performance (Fortier, 2002, p. 44). In this sense performance possesses the attributes of the ghost who/which

\footnotetext{
${ }^{3}$ The question of the present time of performance was addressed by many scholars and critics, e.g. Thornton Wilder, Martin Esslin (referring to Goethe and Schiller), Elam Keir, Peter Szondi, among others.
} 
cannot be located in a precise moment and exists in the state of constant disappearance. Each moment in performance creates an opening, a sense of "being-there of an absent or departed one" (Derrida, 2006, p. 6). This hauntological sense of disappearance defines the ontological status of performance, discussed among others by Peggy Phelan. Phelan argues that performance cannot exist beyond its actual happening and because of that is constituted by both presence and disappearance: “[t]heatrical performance is always bound to the present. For this reason, theatre continually marks the perpetual disappearance of its own enactment" (1993, p. 118). Phelan further suggests that "[p]erformance cannot be saved, recorded, documented, or otherwise participate in the circulation of representations of representations: once it does it becomes something other than performance" (1993, p. 146). The belief in the liveness and immediacy of performance has been criticized, among others, by Philip Auslander, who argues that there is no ontological difference between live and mediated performance and the belief in "performance's disappearance into memory" can equally apply to mediated arts (2008, pp. 184-186). Auslander also discusses a stable pattern according to which a new technology usurps the place of and imitates the live form of art but later provides the model for imitation for live art. Following Walter Benjamin, Auslander observes that the new (the 1990s) kind of expectation of the audience - also in relation to live performance-was the television-generated proximity and intimacy $(2008$, p. 184), which is now replaced with the "affordances of the digital media," which, as Jenkins, Ford and Green argue, "provide a catalyst for reconceptualizing other aspects of culture, requiring the rethinking of social relations, the reimagining of cultural and political participation. ..” (Jenkins, Ford, \& Green, 2013, p. 3). Komuna Warszawa's remix illustrates both of these seemingly contradictory processes, of the spectral disappearance of performance and its transformation into the phantasms generated by the media which replace the presence and immediacy of theatre. In this sense the remix creators deliberately enact the act of disappearance as a form similar to Phelan's concept of active vanishing. ${ }^{4}$

The Paradise Now remix project is built around disappearances. It is based on the strategies of annulling the present time of performance through technological editing and replication. Visual and auditory technologies distance the performers from their own bodies and voices. Spectralizing the live performance is a deliberate strategy exposing the extent to which there is no present time to refer to. In this context the Living Theatre's Paradise Now is a thing of the past. There is no possibility of restoring, recreating or reviving the original authenticity of performance and its direct kinetic and tactile appeal, including the experience of presence with others in the spontaneous, ritualistic communitas (Turner, 1982, p. 48), which was part of the original performance. What is left is a sense of loss,

\footnotetext{
${ }^{4}$ The concept of disappearance is used by Phelan also as a deliberate and conscious strategy of creativity: "I am speaking here of an active vanishing, a deliberate and conscious refusal to take the payoff of visibility" (1993, p. 19). She describes this strategy by the notion of "the unmarked," which refers to what is immaterial and "shows itself through the negative" (Phelan, 1993, p. 19). As a strategy disappearance involves asking questions ofand recognizing — who or what is absent — who or what is not there.
} 
the missing memory which can be only mediated through film and documentation. The aspects of active vanishing in the remix project expose both the inadequacy of the past performance to address contemporary audiences and the inability or even unwillingness of Komuna Warszawa to return and restore the theatrical past. The large screen at the back of the playing area onto which the video interview with aged Judith Malina is projected performs a similar function - of manifesting the chasm between the memory of the Living Theatre, its radical performance, youthful energy and trust in people and its present aging and outdated reality. At the same time, paradoxically despite its mediated nature and editing, the image of Judith Malina appears to be the most authentic element of performance, which after Malina's death in $2015^{5}$ seems to go on living its own spectral existence. The experience of immediacy, proximity and authenticity — or more likely its substitute - is conveyed through a mediated documentary image, not the live performance.

The concept of the present time of a performance can also be discussed in the context of Derrida's commentary on the impossibility of what we call real time. First of all, Derrida argues that "there is never an absolutely real time," but what we call real time is in fact "an extremely reduced différance" (2013, p. 47). And secondly, the only context in which we refer to our living in real time, according to Derrida, is "access precisely to what we are not living: we are there where we are not, in real time, through images or through technical relation" (2013, p. 46). The project realized by Komuna Warszawa experiments with the notion of real time of performance by delayed image projection that separates the living bodies from their performative stage images, the result of which resembles the act of "expanding" the différance. It subversively locates the real time of performance in the spectral past, which it seems both to restore and negate through the simulated reproduction.

\section{Haunted Media and Onstage Digitalization}

Spectral conceptualizations have been productively employed in the discussion of the nature of mediated images and sounds and the article has referred to some of them already. In this section I will refer to two major aspects of the onstage use of video and digital technologies, which are active in Komuna Warszawa's remix. The first one, mostly based on Derrida's reflections, views spectrality of technologies and media as related to death and crisis of existence. The second one connects media spectrality to phantasms, which offer a possibility of presenting what does not yield to representation and which evoke a sense of loss but also offer a creative potential.

In an interview with Bernard Stiegler, Jacques Derrida comments on the spectrality of technology and the media which is based on the miraculous nature of reproduced images and which cannot be undermined or questioned by our knowledge of the processes of their production: "We are spectralized by the shot, captured or possessed by spectrality in advance" (Derrida, 2013, p. 39) before we actually reappear in our mediated image. At this

\footnotetext{
${ }^{5}$ The present analysis is based on the performance given in March 2015, prior to Judith Malina's death.
} 
moment we are already symbolically dead because "we know that, once it has been taken, captured, this image will be reproducible in our absence, because we know this already, we are already haunted by this future, which brings our death" (Derrida, 2013, p. 38). Derrida conceptualizes the participation in the recording, filming and then projection process as miraculous because at the moment of our experience of the mediated/mediating image, we do not activate or perhaps do not wish to use our technical knowledge:

Our disappearance is already here. We are already transfixed by a disappearance [une disparition] which promises and conceals in advance another magic "apparition," a ghostly "re-apparition" which is in truth properly miraculous, something to see, as admirable as it is incredible [incroyable], believable [croyable] only by the grace of an act of faith. Faith which is summoned by technics itself, by our relation of essential incompetence to technical operation. (2013, p. 38)

The technologies used in the remix project generate the effects of spectralization at least on two levels. The primary one refers to the documentary recording of the interview with Judith Malina - first prematurely spectralized by technological reproduction and thenafter her demise - belatedly materialized in a video projection ${ }^{6}$. A more self-referential level is activated in the scene of filming and projecting images of live performance on the screen, mentioned earlier. Because during the performance the technical team and equipment are part of the onstage activities, the technical process loses the "magical" quality of which Derrida was talking in an interview. In fact, the exposed technical procedures seem to guarantee the authenticity of the reproduced images: we see the original, witness the recording and editing process, watch the projection and verify the equivalence of the two. However, we are further invited to extend this equivalence to the original performance of the Living Theatre, which can only be done by an act of faith. At this point, the very process of digitalization and mediation becomes self-referential in the manner of the regenerative remix, mentioned at the beginning of this article. The object to which the projected image refers (the original performance) is ostensibly absent, already dead and additionally spectralized by the vacuum that its intentionally failed reproduction produces.

In his commentary on spectrality, Julian Wolfreys defines the spectral as "that which makes possible reproduction even as it also fragments and ruins the very possibility of reproduction's apparent guarantee to represent that which is no longer there fully" (2002, p. 2). What makes the whole spectralizing process possible in Komuna Warszawa's remix project is the prior disappearance and transformation of the original into the documentary image. In this perspective the performance by Komuna Warszawa tries to reconstruct and duplicate the documentary process of the production and reproduction of the original and

\footnotetext{
${ }^{6}$ In the scene of a partly improvised interview in Ghost Dance (1983), directed by Ken McMullen, Derrida talks of himself as spectralized by being filmed and recorded, speaking the voice of the other. It is both disturbing and deeply ironic that an actress who was acting in the scene with Derrida-Pascale Ogier-died a year after the premiere. Derrida describes the double level of spectrality in the experience of re-watching the film afterwards (2013, p. 40). A similar effect expanding the spectrality of the Paradise Now remix is generated in seeing the production after Judith Malina's death, increasing the ethical dubiousness of using the video featuring elderly Malina in the performance.
} 
its black and white archival copy. It seems that for that reason the whole stage behind the transparent screen with the exception of the film presenting Malina imitates the range of colours available in black and white photography.

Technology in Komuna Warszawa's project and particularly in the onstage digitalization scene-despite its self-referential and self-annulling qualities - offers perhaps a more effective attempt at embracing the concept of paradise as phantasmatic opening of the invisible than the ironic, humorous and self-consciously irreverent lectures on the concept and probability of paradise delivered by an actor in front of the transparent screen. The screen projections of the actors' figures in Komuna Warszawa's performance in a way resemble the spectral effects produced by a system of reflections in the Pepper's ghost illusion. The ghostly, generated by technological means, as Tom Gunning argues in his study of the ontology of mediated vision through the prism of pre-modern categories, "fascinates us as a complex of two fundamental fantasies": of the phantasmatic body and of untimely presence (2013, p. 232). The former undermines our ability to uphold the separation between the material and the incorporeal while the latter juxtaposes the untimeliness of haunting with the other forms of the return of the past, such as memory or history (Gunning, 2013, p. 232). If we take Komuna Warszawa's project to be primarily based on phantasm reconstruction/production it operates along the line of melancholic attempt at hallucinatory return of the lost object (Gunning, 2013, p. 236) - in this case both the belief in the concept of utopia and social paradise and the possibility of reactivating immediate political theatre in the no longer innocent times of scepticism, self-awareness and digital reproduction.

\section{Conclusion}

Paradise Now? RE//MIX endeavours to re-visualize - through replication and the use of modern technologies - what has disappeared in time only to increase the melancholic sense of the thing that is gone. In doing so the project demonstrates the spectral inadequacy and irrelevance of the past political theatre to the present reality. The technological transformation of the recorded videos and the live performance both fragments and deconstructs the political utopian message of the Living Theatre's original performance, while teasing at times with the possibilities of computer generated image reconstruction and imitation. The sense of disappearance that the performance evokes does not signify the possibility of disregarding the type of theatre or thought that seems to have no appeal any more. In fact, following Fredric Jameson, one could say that the performance makes us aware of the extent to which our present is not "as self sufficient as it claims to be" (2008, pp. 39-58).

The remix formula on which the whole project is based relies on comparison, confrontation and active memory of the original. However, it refers to the memory that cannot be activated without the help of documentation. Once memory is artificially reproduced, it shows how inaccessible it is in any direct performative experience. Yet the futility of the reconstructive process is counterbalanced by its creative possibility. In a way, the technological spectrality of Komuna Warszawa's performance also lends itself to the pre-modern 
logic of the phantasm, which, as Gunning argues, "gains a new valency" in "the proliferation of virtual images" (2013, p. 211). The phantasm that is technologically and conceptually created through the new media "mediates between presence and absence, possession and loss, reality and sign, opening up a realm not only of mourning and symbolic action but also of play and artistry" (Gunning, 2013, p. 236). Komuna Warszawa's performance transfers or perhaps restores the concept of paradise, concretized in social and political action in the Living Theatre's performance, into the technological sphere of the phantasmatic, more indefinite, accommodating and detached.

\section{References}

Auslander, P. (2008). Liveness: Performance in a mediatized culture. Abington, UK: Routledge.

Brook, P. (1990). The empty space. London, UK: Penguin Books.

Carlson, M. (2003). The haunted stage: The theatre as memory machine. Ann Arbor: University of Michigan Press.

Derrida, J. (2006). Specters of Marx: The state of the debt, the work of mourning and the new international. (P. Kamuf, Trans.). New York, NY: Routledge.

Derrida, J. \& Stiegler, B. (2013). Spectrographies. In M. del Pilar Blanco \& E. Peeren (Eds.), Spectralities reader: Ghosts and haunting in contemporary cultural theory (pp. 37-51). London, UK: Bloomsbury.

Fortier, M. (2002). Theory/theatre: An introduction. London, UK: Routledge.

Gałązka, A. (2014). Autodokumentacja: Raj teraz. In T. Plata \& D. Sajewska (Eds.), RE//MIX: Performans i dokumentacja (pp. 218-219). Warsaw, Poland: Wydawnictwo Krytyki Politycznej.

Gunning, T. (2013). To scan a ghost: The ontology of mediated vision. In M. del Pilar Blanco \& E. Peeren (Eds.), Spectralities reader: Ghosts and haunting in contemporary cultural theory (pp. 207-244). London, UK: Bloomsbury.

Innes, C. (1984). Holy theatre: Ritual and the avant-garde. Cambridge, UK: Cambridge University Press.

Innes, C. (1993). Avant-garde theatre: 1892-1992. London, UK: Routledge.

James, K. (2016). Mapping critical media literacy onto iterative remix practice. In P. Ruggiano Smith \& A.M. Lazar (Eds.), Reconceptualising literacy in the new age of multiculturalism and pluralism (pp. 125-150). Charlotte, NC: IAP.

Jameson, F. (2008). Marx's purloined letter. In M. Sprinker (Ed.), Ghostly demarcations: A symposium on Jacques Derrida's Specters of Marx (pp. 26-67). London, UK: Verso.

Jenkins, H., Ford, S., \& Green, J. (2013). Spreadable media: Creating value and meaning in a network culture. New York, NY: New York University Press.

Keir, E. (2002). The semiotics of theatre and drama. London, UK: Routledge. 
Komuna Warszawa. (2015a). Paradise Now? RE//MIX Living Theatre (Live performance). Torun, Poland: Klamra Theatre Festival.

Komuna Warszawa. (2015b). RE// MIX cycle (started in 2010). Retrieved May 5, 2017 from http://komuna.warszawa.pl/1998/12/12/re-mix-cycle-20102011/

Lorek-Jezińska, E. (2013). Hauntology and intertextuality in contemporary British drama by women playwrights. Torun, Poland: Nicolaus Copernicus University Press.

Łuksza, A. (2014). Próba zapisu: Komuna//Warszawa: Paradise Now? RE//MIX Living Theatre. In T. Plata \& D. Sajewska (Eds.), RE//MIX: Performans i dokumentacja (pp. 213-217). Warsaw, Poland: Wydawnictwo Krytyki Politycznej.

Navas, E. (2012). Remix theory: The aesthetics of sampling. Vienna, Austria: Springer.

Pasquier, M.-C. (1987). Wspótczesny teatr amerykański. (E. Radziwiłłowa, Trans.). Warsaw, Poland: Państwowy Instytut Wydawniczy.

Phelan, P. (1993). Unmarked: The politics of performance. London, UK: Routledge.

Plata, T., \& Sajewska, D. (2014). RE//MIX Intro. In T. Plata \& D. Sajewska (Eds.), RE//MIX: Performans i dokumentacja (pp. 9-17). Warsaw, Poland: Wydawnictwo Krytyki Politycznej.

Roose-Evans, J. (1973). Experimental theatre: From Stanislavsky to Peter Brook. London, UK: Studio Vista.

Turner, V. (1982). From ritual to theatre: The human seriousness of play. New York, NY: Performing Arts Journal Publications.

Tylell, J. (1995). The living theatre: Art, exile and outrage. New York, NY: Grove Press.

Weinstock, J. A. (2013). Introduction: The spectral turn. In M. del Pilar Blanco \& E. Peeren (Eds.), Spectralities reader: Ghosts and haunting in contemporary cultural theory (pp. 62-63). London, UK: Bloomsbury.

Wolfreys, J. (2002). Victorian hauntings: Spectrality, Gothic, the uncanny and literature. Basingstoke, UK: Palgrave. 